Ensino, Saúde e Ambiente - V9 (3), pp. 54-63, Dez. 2016

\title{
PERCEPÇÃO DE MACROFUNGOS POR ESTUDANTES DE UMA ESCOLA PUBLICA NO NORDESTE DO BRASIL.
}

\section{PERCEPTION OF MACROFUNGI BY STUDENTS IN A PUBLIC SCHOOL FROM NORTHEAST OF BRAZIL.}

\author{
Tony César de Sousa Oliveira ${ }^{1}$, Claudiana Pereira da Silva², Thales Eduardo Galdino \\ Andrade $^{3}$, Raelson Filipy Martins Santos ${ }^{4}$, Adriana de Sousa Lima ${ }^{5}$, José de Ribamar de \\ Sousa Rocha ${ }^{6}$ \\ ${ }^{1}$ Universidade Federal do Piauí /Programa de Pós-Graduação em Desenvolvimento e Meio Ambiente, \\ tonycsoliveira@hotmail.com.br \\ 2 Universidade Federal do Piauí/ Programa de Pós-Graduação em Genética e Melhoramento, \\ claudianasilvapereira123@gmail.com \\ ${ }^{3}$ Universidade Federal do Piauí/ Programa de Pós-Graduação em Genética e Melhoramento, \\ thalesgaldino@hotmail.com \\ ${ }^{4}$ Graduado em Ciências Biológicas- Universidade Federal do Piauí, raelsonfilipy@gmail.com \\ ${ }^{5}$ Mestre Desenvolvimento e Meio Ambiente, professora da Faculdade do Médio Parnaíba, \\ adrianabiologa@gmail.com \\ ${ }^{6}$ Universidade Federal do Piauí, Departamento de Biologia da - Laboratório de Fungos Zoospóricos, \\ ribamar10@hotmail.com
}

\section{RESUMO}

Buscou-se observar a forma como alunos de uma escola rural de ensino médio no nordeste do Brasil classificam e idealizam os macrofungos. Os dados foram obtidos por meio de questionários semiestruturados aplicados a 92 alunos, acompanhado de um incentivo visual. Ao analisar as imagens os estudantes, em sua maioria, consideraram os fungos pertencentes a outros reinos, como Plantae e Monera. Isso evidencia que apesar de serem alunos de ensino médio, estes possuem descrição própria para esse reino, onde o conhecimento de mundo se sobressai ao científico.

Palavras-chave: Micologia. Percepção. Ruralidade.

\begin{abstract}
It was attempted to observe how students from a high school in a rural area in northeastern Brazil classify and idealize macrofungi. Data was collected through semistructured questionnaires to 92 students, accompanied by a visual incentive. When analyzing the images the students mostly considered fungi belonging to other realms as Plantae and Monera. This shows that although they are high school students, they have their own description of this kingdom, where the knowledge of the world surpasses the scientific knowledge.
\end{abstract}

Key words: Mycology. Perception. Rurality.

\section{INTRODUÇÃO}

Segundo Guivant (2000) a sociologia ambiental, em sua perspectiva construtivista, busca entender como as pessoas atribuem significados ao mundo que pertencem e convivem. Diferentes grupos culturais vêm se apropriando do meio 


\section{Ensino, Saúde e Ambiente - V9 (3), pp. 54-63, Dez. 2016}

ambiente (SILVA e FRAXE, 2013), e esse movimento faz com que esses grupos gerem classificações e percepções específicas para solucionar os problemas enfrentados no cotidiano, isso ocorre por meio do estabelecimento de interações com os ambientes nos quais estão inseridos (OREY e ROSA, 2014). O aluno não foge a esse padrão, pois é comum e natural à infância e adolescência a busca por explicações para determinados eventos que ocorrem na natureza.

A análise das formas concretas pelas quais essas diferentes formações culturais se apropriam do meio onde se desenvolvem vem sendo alvo de grande interesse dentro da ciência. Essa apreciação ocorre através da etnociência, uma ciência interdisciplinar a qual parte de ferramentas teóricas para a reconstrução histórica das relações sociedade natureza (LEFF, 2009).

Essa ciência propõe uma nova abordagem antropológica por meio da qual as culturas não são mais vistas somente como uma coleção de artefatos e um conjunto de normas comportamentais, mas passaram a ser consideradas como um sistema de conhecimento, que pode ser revelado por meio de suas estruturas linguísticas (SILVA e FRAXE, 2013). O conhecimento passou a ser considerado, então, como um conjunto de habilidades e competências que são transmitidas através das gerações.

Dentro deste contexto, surge a etnobiologia que, para Barros (2012), é uma ciência interdisciplinar, que navega na fronteira entre as Ciências Sociais e as Ciências Naturais, tendo como objetivo central entender como as sociedades humanas utilizam e percebem o ambiente natural que está em sua volta. Esta sofreu várias ramificações, dentre elas tem-se a etnomicologia, uma disciplina que lida com o estudo das relações entre os seres humanos e fungos (MORENO FUENTES et al, 2001).

Os fungos estão entre os grupos de organismos mais diversos e versáteis (QUEIROZ et. al., 2006), além de serem de extrema importância para a manutenção da vida no planeta (SILVA e COELHO, 2006). Porém, é bem comum acontecerem conflitos em relação a esse reino dentro das salas de aula, porque a forma como a maioria dos estudantes compreende o ambiente que vive não é compatível ao modo como as ciências descrevem e explicam o mundo (BAPTISTA e EL-HANI, 2007).

Esse táxon causa equívocos até mesmo dentro da ciência moderna, pois ele possui uma grande mobilidade, onde ora é caracterizado como parte do Reino Plantae, ora assumindo posição de grupo autônomo. Podemos observar isso nos livros destinados ao ensino superior, como por exemplo, Biologia Vegetal, de autoria de 


\section{Ensino, Saúde e Ambiente - V9 (3), pp. 54-63, Dez. 2016}

Raven et al. (2001), que trazem conteúdos de micologia abordados junto ao Reino Plantae.

Em se tratando de fungos, eles demonstram ter grande utilidade para o meio ambiente devido a sua função de decompositor, e para o homem social, no caso dos microfungos, cuja importância para as culturas humanas pode ser notada através do controle biológico e micorrizas, na agricultura, dermatófitos em clínicas, utilizáveis na indústria alimentar, etc. (OLIVEIRA, 2001)

Este uso não compete somente aos dias atuais, uma vez que o Tratado Internacional sobre os Recursos Fitogenéticos para a Alimentação e a Agricultura (FOOD AND AGRICULTURE ORGANIZATION OF THE UNITED NATIONS, 2009) mostra que durante milhares de anos, mais de 10 mil espécies de plantas e fungos foram utilizados pela sociedade.

Sabendo que os fungos apresentam características específicas que os agrupam em um reino próprio, e que esses organismos estão relacionados à vivência e experiência próprias em cada comunidade, além da sua importância para o meio e para a sociedade, procurou-se retratar como alunos de uma escola pública localizada no município de Curralinhos-PI, nordeste do Brasil, idealizam os macrofungos a partir da sua vivência com o ambiente natural e acadêmico.

\section{METODOLOGIA}

A pesquisa foi desenvolvida no município de Curralinhos, na região norte do Piauí, Nordeste do Brasil, que possui uma população de 4.182 habitantes, com área territorial de $345.848 \mathrm{~km}^{2}$ e uma densidade demográfica de 12,02 hab $/ \mathrm{km}^{2}$. O município se encontra a uma distância de $68 \mathrm{~km}$ de Teresina, capital do Estado (IBGE, 2010), limitando-se ao norte com os municípios de Nazária, Teresina e Palmeirais; ao sul com São Pedro do Piauí e Miguel Leão; ao leste com Monsenhor Gil e oeste com Palmeirais.

O lócus da pesquisa foi a Unidade Escolar Menino João Pedro, uma escola pertencente à rede estadual de ensino, que no ano de 2015 possuía duas turmas de $1^{\circ}$ ano, duas de $2^{\circ}$ ano e duas de $3^{\circ}$ ano. Vale ressaltar que esta unidade de ensino funciona como escola polo, pois além de atender os alunos da própria cidade (zona urbana), oferece também vagas para a zona rural e comunidades de municípios vizinhos.

De início, ocorreu uma visita prévia à escola onde foi exposto ao diretor e ao professor a forma de trabalho a se desenvolver. No ato, foram-lhes entregues os Termos 
de Concessão para a realização da pesquisa com os alunos da escola e, após a liberação, ocorreu o primeiro contato com os discentes. Foi realizado um convite aos estudantes para participarem da pesquisa e foi explicado o objetivo e a metodologia que seria aplicada durante o trabalho. Posteriormente, foi entregue e lido o Termo de Consentimento Livre Esclarecido (TCLE), para que os alunos ou responsáveis pudessem ler e assinar, em concordância, sendo-lhes garantido total sigilo.

A coleta de dados foi obtida com a utilização de entrevistas baseadas em questionário semiestruturado open-ended (aberto) (ALBUQUERQUE et. al. 2010) com 92 alunos. Após a aplicação do questionário sobre conhecimento de macrofungos seguiu-se com auxílio de testes projetivos, semelhantes aos de Nogueira (2012), quando mostrou-se um painel com diferentes imagens de Basidiomicetos. Segundo Medeiros et al. (2010), esses estímulos visuais estão presentes em cerca de 57,8\% das pesquisas etnobiológicas, onde $22,2 \%$ dessas utilizam as fotografias como estratégia de pesquisa, como a utilizada nesse trabalho. O questionário também caracterizou o perfil socioeconômico dos informantes.

Os dados quantitativos coletados foram organizados em tabelas do Microsoft Excel 2010, em seguida estes foram analisados, interpretados e categorizados com apresentação dos valores em porcentagem e expressados em gráficos e tabelas. Também foi realizada uma análise qualitativa, para uma melhor interpretação dessa percepção.

\section{RESULTADOS E DISCUSSÕES}

A faixa etária dos alunos é de 14 e 24 anos, cujas idades mais representativas foram de 15 anos (28\%), 16 anos (24\%) e 17 anos (18\%). Desses, 69\% pertencem à zona rural, pois, como já mencionado, a escola é a única do município que recebe alunos da zona urbana, zona rural e até de municípios vizinhos.

Após a apresentação das imagens, os alunos agruparam os macrofungos nas seguintes categorias taxonômicas: 52\% afirmaram serem plantas, 29\% dizem que são fungos, $15 \%$ classificaram como bactérias, $2 \%$ os classificaram como vírus e os outros $2 \%$ não souberam opinar (figura 1). 
Figura 1. Denominação taxonômica de um basidiomiceto por estudantes da Unidade Escolar Menino João Pedro, Curralinhos-Piauí, 2016.

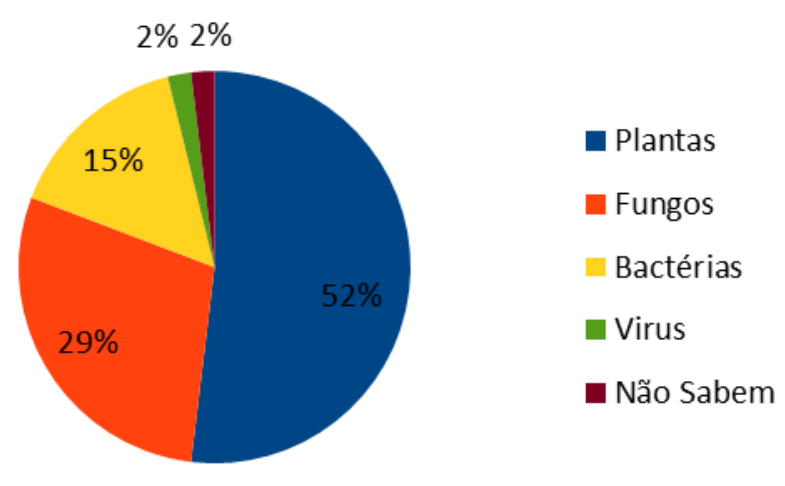

Fonte: Autor

Existem poucos trabalhos referentes à essa classificação de fungos em comunidades no Brasil, mais precisamente no nordeste. No estado do Piauí, existe um único trabalho realizado por Barbosa et al. (2015) e seus resultados se mostraram bem diferentes dos encontrados nesta pesquisa, ou seja, apenas $17 \%$ dos entrevistados os classificaram como plantas, $2 \%$ os reconhecerem como fungos e $81 \%$ os desvincularam de fungos e plantas.

Um dos fatores que levam à essas diferenças em porcentagem talvez se deva à diferença etária entre os entrevistados, visto que $61 \%$ dos que organizaram os macrofungos como diferentes de plantas e animais no trabalho dos referidos autores, baseados no critério de divisão dos grupos por faixa etária (IBGE, 2010), são considerados idosos, enquanto $100 \%$ dos nossos entrevistados, baseados nos mesmos critérios, são considerados jovens (entre 18 e 24 anos).

Percebeu-se por meio desses dados, que o conhecimento holístico ofertado pelo sistema de ensino da escola pesquisada, no que se refere à Micologia, trouxe aos alunos uma certa melhora na percepção dos fungos, embora tímida, quando comparado aos resultados dos autores citados à cima, apesar de boa parte dos alunos por eles entrevistados possuírem a influência não só dos conhecimentos acadêmicos, mas também um tempo maior de conhecimento empírico adquirido ao longo da vida. 


\section{Ensino, Saúde e Ambiente - V9 (3), pp. 54-63, Dez. 2016}

Outro aspecto que merece atenção é o fato de que, igualmente aos moradores da comunidade Zabelê, esses alunos também enquadraram os Fungos ao Reino Plantae. Os autores justificaram essa resposta devido às influências exógenas, como o nível de escolaridade (BARBOSA et al, 2015). Porém, a amostragem foi composta por alunos de todas as séries do ensino médio da referida unidade de ensino, indivíduos que tiveram contato recente com os conteúdos de micologia, retratando a forte influência da cultura dentro do processo de ensino e aprendizagem, mostrando que o professor não conseguiu levar esses alunos a cruzar suas fronteiras culturais (AIKENHEAD, 1996). O equívoco na troca dos reinos Fungi e Plantae pode ser o resultado do conteúdo sobre fungos ser abordado próximo do conteúdo de plantas, ou por haver livros de botânica em que se trabalha o Reino Fungi (RIBEIRO,CAETANO e MEGLHIORATTI, 2010).

Rosa e Mohr (2010), ao analisarem os conteúdos de Micologia, observaram pequenos erros nas coleções didáticas brasileiras, indicando a necessidade de reformulações e aprimoramentos destas para um melhor aproveitamento. Para isso, Lemos (2008) sugere que, para se trabalhar o Reino Fungi na escola é necessário inicialmente compreender que a sua natureza é dinâmica, sistêmica e complexa, e demanda uma relação dialética entre as partes e o todo, fazendo assim com que os alunos possam enxergar as características específicas desses seres.

Moreira et al (2007) ressaltam ainda a importância de que os professores estejam atentos ao grande distanciamento que pode se estabelecer entre o mundo da ciência e o mundo do cotidiano, uma vez que, essa distância poderá se tornar ainda maior devido ao academismo exagerado da escola.

Os macrofungos são comumente classificados por populações tradicionais, levando em consideração a linguagem específica de cada cultura (BARBOSA et al., 2015), e quando questionados, os principais nomes dos macrofungos que esses discentes conhecem e os locais que eles vivem, cerca de $62 \%$ os chamaram de frieira, essa denominação se dá devido a um conhecimento local de que o contato com esse fungo pode causar uma doença conhecida na região como frieira (uma micose causada pelo fungo Trichophyton, conhecida também como pé de atleta). Essa nomenclatura também é utilizada por alunos no trabalho de Johan et al (2014), cujos $25 \%$ os denominaram como Cogumelos, e essa denominação provavelmente se deu pelo que é exposto no livro didático e também pela influência midiática; os outros $8 \%$ relataram sobre a Orelha de Pau (Quadro 1). 
Quadro 1: Principais macrofungos e locais encontrados citados por estudantes da Unidade Escolar Menino João Pedro, Curralinhos-Piauí, 2016.

\begin{tabular}{|l|c|l|}
\hline Nome & $\%$ & Ambiente \\
\hline Frieira & 67 & Ambiente úmido \\
\hline Cogumelo & 25 & Ambiente úmido \\
\hline Orelha de Pau & 8 & Todo tipo de Ambiente \\
\hline Total & 100 & \\
\hline
\end{tabular}

Cerca de $92 \%$ dos alunos associaram a presença de fungos ao período de chuvas. Segundo eles, a umidade tem grande influência no aparecimento desses seres vivos, principalmente os de maior porte como os basidiomicetos. Se tratando desses indivíduos, os estudantes relataram que sempre os encontram próximos a "Arvores Mortas" (JM, aluno de $1^{\circ}$ ano), meio a folhas secas (LO, aluno de $3^{\circ}$ anos) e "Dentro de Currais" (Locais onde ficam bovinos e caprinos) (SC, aluna de $1^{\circ}$ ano).

Observa-se que a etnobiologia e a sociologia ambiental rural se mostram unidas em um diálogo para se trabalhar propostas interdisciplinares voltadas, em especial, ao estudo das múltiplas relações sociedade-ambiente. O olhar para o ambiente escolar se mostra como essencial para a perpetuação da sustentabilidade, e entender como a futura geração enxerga o meio é a melhor forma de propor políticas públicas para um futuro mais sustentável, cabendo a escola ser a base dessa perpertuação do conhecimento.

Debord (1997, p. 182) diz que “O desenvolvimento dos conhecimentos da sociedade, que contém uma compreensão da história como o cerne da cultura, adquire por si só um conhecimento sem retorno(...)", portanto, conhecer o saber da futura sociedade é ter acesso a um rico acervo de estratégias para a elaboração de um manejo sustentável.

\section{CONCLUSÃO}


O presente estudo evidenciou, que apesar de serem alunos do ensino médio, estes possuem descrições específicas para esse reino, como apresentação de características predominantemente morfológicas e substratos no qual podemos encontrálos, mostrando que o conhecimento tradicional se sobressai ao conhecimento científico. Esses resultados corroboram com as informações de trabalhos etnobiológicos, de que o homem organiza a natureza a partir do contato com o meio ambiente.

A Etnobiologia é uma ferramenta que pode ser utilizada pelos docentes dentro o processo de ensino-aprendizagem, não só apenas com instrumento de avaliação diagnóstica, mas também como uma ferramenta que gere entendimento para conduzir um diálogo entre o conhecimento cotidiano e a prática pedagógica.

A utilização dos conhecimentos etnobiológicos na sala de aula podem abrir possibilidades para uma interlocução entre o conhecimento empírico dos discentes com os conteúdos de biologia. Desta maneira, é possível entender que a Etnobiologia é uma ferramenta que viabiliza a compreensão do conteúdo, não apenas com alunos do ensino médio, mas de todo o ensino básico, principalmente com os de ensino fundamental, uma vez que esses debates podem entusiasmar os alunos e articular a teoria à prática.

\section{REFERÊNCIAS}

AIKENHEAD, G. S. Science education: Border crossing into the sub culture of science. Studies. Science Education, vol. 27, 1996, p. 1-52.

ALBUQUERQUE, U. P.; LUCENA, R. F. P.; ALENCAR, N. L. Métodos e técnicas pra coleta de dados biológicos. In: ALBUQUERQUE, U. P. ;LUCENA, R. F. P.; CUNHA. L. V. F. C. (org) Métodos e Técnicas na pesquisa Etnobilógica e Etnoecológica. Recife PE: NUPEEA, 2010.

BAPTISTA, G. C. S. ; EL-HANI, C. N. Diálogo entre modos de conhecer no ensino de Biologia: Estudo de caso numa escola pública do estado da Bahia.. In: VI ENPEC, 2007, Florianópolis-SC. Anais do VI Encontro Nacional de Pesquisa em Educação em Ciências (ENPEC). Minas Gerais-MG: ABRAPEC, 2007. v. 1.

BARROS, F. B. Etnoecologia da pesca na reserva extrativista riozinho do anfrísio terra do meio, Amazônia, Brasil. Amazônica. n. 4 (2), 2012. p. 286-312.

CEPRO - Fundação Centro de Pesquisas. Perfil dos municípios, Curralinhos-PI: Fundação CEPRO, 2001.

DEBORD, G. A sociedade do espetáculo. Rio de Janeiro. Contraponto. 13 ed. 1997. FOOD AND AGRICULTURE ORGANIZATION OF THE UNITED NATIONS (FAO). Tratado Internacional sobre los Recursos Fitogenéticos para la 
Alimentación y la Agricultura. 2009. Disponível em <ftp://ftp.fao.org/docrep/fao/011/i0510s/i0510s.pdf> Acesso em 28. jun. 2016.

GUIVANT, J. S. Contribuições da sociologia ambiental para os debates sobre desenvolvimento rural sustentável e participativo. Estudos Sociedade e Agricultura (UFRJ), Rio de janeiro, v. 19, p. 72-88, 2002.

IBGE - INSTITUTO BRASILEIRO DE GEOGRAFIA ESTATÍSTICA. Cidades IBGE: Curralinhos-PI. Disponível em >http://cidades.ibge.gov.br/xtras/perfil.php?codmun=220325< Acesso em 20 de fev de 2016.

JOHAN, C. S.; JOHAN, C. S. ; CARVALHO, M. S. ; ZANOVELLO, R. ; OLIVEIRA, R. P.; GAIRLET, T. M. B.; BARBOSA N. B ; MORESCO, T . Promovendo a aprendizagem sobre fungos por meio de atividades práticas. Ciência e Natura, v. II, p. 798-805, 2014.

KONDER, L. O Futuro da Filosofia da Praxis: o pensamento do marxismo no século XXI. Rio de Janeiro: Paz e Terra, 1992

LEFF, E. Ecologia, Capital e Cultura: a territorialização da racionalidade ambiental. Editora Vozes, Petrópolis - RJ. 2009.

LEITE, I. A.; DE MORAIS, A. M.; CARNEIRO, R. G.; LEITE, C. A. A etnobotânica de plantas medicinais no município de São josé de Espinharas, Biodiversidade. João Pessoa-PB, Brasil, 2015.

LEMOS, E. S. El aprendizaje significativo y la formación inicial de profesores de Ciencias y Biología. Burgos, 2008. 345f. Tese (Doutorado em Ensino de Ciências) Universidade de Burgos, Burgos, 2008.

MEDEIROS. P. M, et al. Uso de estimulos visuais na pesquisa etnobiológicas, in, ALBUQUERQUE, U.P. LUCENA, R. F. P.; CUNHA. L. V. F. C. (org) Métodos e Técnicas na pesquisa Etnobilógica e Etnoecológica. Recife PE: NUPEEA, 2010.

MOREIRA, K. C. et al. O desenvolvimento de aulas práticas de química por meio da montagem de Kits experimentais. In: PINHO, S. Z.; SAGLIETTI, J. R. C. (Org.). Livro eletrônico dos Núcleos de ensino da UNESP - edição 2007. São Paulo. 2007

MORENO-FUENTES, A., R. GARIBAY-ORIJEL, J. TOVARVELASCO y J. CIFUENTES. . Situación actual de la Etnomicologíaen México y el mundo. Etnobiología, Núm. 1, pp. 75-84 2001.

NOGUEIRA, T, M. Estudo Etnoentomológico com os Quilombolas do Povoado de Mesquita, Goiás, Brasil. 2012. (Trabalho de Conclusão de Curso) - Universidade Estadual de Goiás. 2012 
OLIVEIRA, P. Cogumelos e o Ambiente. Diário do Sul, página «Naturalmente», 3 de MAIO de 2001.

RAVEN, P.H.; EVERT, R.F.; \& CURTIS, H. Biologia Vegetal.6a ed. Ed. Guanabara Koogan S.A. Rio de Janeiro. 2001

RIBEIRO, D. G.; CATANEO, M. P.; MEGLHIORATTI, F. AP. A construção conceitual sobre fungos e decomposição em aulas teórico - práticas no ensino médio in: Os estágios supersionados de ciências e biologia em debate II, 2010, cascavel. Os estágios supersionados de ciências e biologia em debate II. Cascavel: Edunioeste, 2010. v. único.

ROSA, M. D. MOHR, A. Os fungos na escola: análise dos conteúdos de micologia em livros didáticos do ensino fundamental de Florianópolis. Experiências em Ensino de Ciências 5(3): 95-102, 2010.

SANTOS-FITA, D. Cobra é inseto que ofende: classificação etnobiológica, questões sanitárias e conservação na região da Serra da Jibóia, Estado da Bahia, Brasil. 2008. 133 f. Dissertação (Mestrado em Zoologia) - Universidade Estadual de Santa Cruz, Ilhéus, 2008.

SILVA, R.R. ; COELHO, G. D. . Fungos: principais grupos e aplicações biotecnológicas. In: Tania Maria Cerati. (Org.). Publicações Didáticas. 2006, Disponivel em >http://www.biodiversidade.pgibt.ibot.sp.gov.br/Web/PublicacoesDidaticas.aspx < Acesso em 08 de Fev de 2016.

SILVA, F. J. P. \& FRAXE. T, J. Saberes de populações tradicionais: etnociência em processos de bioconservação. Contribuciones a las Ciencias Sociales. , v.21, p. Diponível em > http://www.eume - 2013 < Acesso em 05 de Fev de 2016.

SOUSA, S. B.; LUCENA, R. F. P.; BARROS, R. F. M.; ROCHA, J. R. S.. Classificação Folk dos macrofungos por uma comunidade rural, Nordeste do Brasil. Revista Espacios , v. 36, p. 18-30, 2015.

OREY, D. C. ; ROSA, M. Aproximando Diferentes Campos De Conhecimento Em Educação: A Etnomatemática, A Etnobiologia e a Etnoecologia. Vidya (Santa Maria. Impresso) , v. 34, p. 1-14, 2014

QUEIROZ L P; RAPINI A; GUILIETTI A M.. Rumo ao Amplo Conhecimento da Biodiversidade do Semiárido Brasileiro. Ministério da Ciência e Tecnologia, Brasília, Brasil 2006.

ZAPPES, C.A.; GATTS, C.E.N.; LODI, L; ANDRIOLO, A. \& DI BENEDITTO, A.P.M. Interações entre o golfinho-nariz-degarrafa (Tursiops truncatus) e a pesca artesanal no Arquipélago das Cagarras e áreas adjacentes, Rio de Janeiro, Brasil.

Sitientibus série Ciências Biológicas 11: 4-30 2011 